\title{
Patagonia-Aysén en la construcción del imaginario geográfico de la nación*
}

\author{
Patagonia-Aysén in the \\ construction of the nation imaginary
}

Andrés Núñez González ${ }^{* *}$

Pontificia Universidad Católica de Chile, Santiago, Chile ORCID: https://orcid.org/0000-0002-166I-845X Enrique Aliste Almuna*** Universidad de Chile, Santiago, Chile ORCID: https://orcid.org/oooo-0002-4085-9093

Álvaro Bello Maldonado ${ }^{\star * * *}$ Universidad de la Frontera, Temuco, Chile

ISSN: ISSN-OI85-4259; e-ISSN: 2007-9I76 DoI: http://dx.doi.org/IO.28928/ri/762014/aot2/nunezgonzaleza/alistealumnae/bellomaldonadoa

\section{Resumen}

El presente artículo se plantea que el territorio de Patagonia-Aysén (Chile) no es un área naturalmente periférica sino que aquella condición es el resultado de una producción histórico-geográfica que la fue constituyendo en una espacialidad periférica. El texto identifica los procesos de producción de imaginarios geográficos desde una perspectiva estado-centrista y concluye que la geograficidad de Patagonia-Aysén debe comprenderse dentro de los marcos sociales desde donde surge la construcción de sentido.

Palabras clave: fronteras, globalización, local, identidad, interculturalidad

\begin{abstract}
This paper proposes that the territory of Patagonia-Aysén (Chile) is not naturally a peripheral area but -instead- the result of a historical-geographical production that constructed as a peripheral spatiality. The text identifies the production processes of fixed geographical imaginaries in a state-centered perspective and concludes that the territory of Patagonia-Aysén can be explained by the social frames from where it is projected.
\end{abstract}

Key words: borders, globalization, local, identity, interculturality

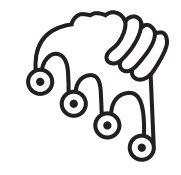

\section{IZTAPALAPA}

Agua sobre lajas

Texto posible gracias al apoyo de CONICYT, del proyecto FONDECYT Regular núm. II41169 (2014-2016),"Fronteras tardías, fronteras actuales: el territorio de Aysén en la construcción del imaginario geográfico de la nación". Chile, siglos xx y xxI.

**aanunezg@uc.cl

*** ealiste@uchilefau.cl

**** a.bello.maldonado@ ufrontera.cl 
"El ser que puede ser comprendido es lenguaje" Hans G. Gadamer

$L$ a relación entre el discurso social y el territorio ha ido adquiriendo cada vez mayor atención de parte de los geógrafos, aunque, sin duda, ello no es ajeno a la tendencia más amplia que se constata en diversas ciencias sociales. Ciertos cambios en las ciencias sociales, y por lo mismo en la geografía, han permitido superar la prenoción que encasillaba a esta disciplina al ámbito de lo físico o de la materialidad más evidente, para involucrarla en miradas socio-culturales y humanísticas. Un elemento sustancial de este tránsito se relaciona con lo que Maurice Halbwachs denominó "los marcos sociales de la memoria" (2004 [1925]), en referencia a que los procesos de percepción de las cosas, y por tanto también del espacio, están mediados por la memoria colectiva o social que nos representa, cual escenario, lo que comprendemos como "verdadero o real". Desde esta posición, el espacio -objeto de estudio del análisis geográfico- deja de ser algo ajeno al sujeto observador para transformarse en el resultado de la interpretación, siempre producida dentro de un contexto socio-cultural dado. De este modo, el espacio ha pasado a concebirse bajo la lógica de las representaciones sociales, que no son estables ni monolíticas. Por lo mismo, se ha alejado de las concepciones positivistas decimonónicas, donde "lo geográfico" correspondía únicamente al "objeto" que se hallaba frente a un sujeto puro e incontaminado.

Desde una renovada plataforma geográfica de este tipo se viene destacando la estrecha e inevitable relación temporalidad-espacialidad. Ello ha repercutido directamente en la concepción que del espacio se ha ido desarrollando en las otras ciencias sociales. De este modo resulta cada vez más recurrente la idea de una espacialidad cuyo sentido deja de ser único e inmóvil para reconocerse su finitud y radical historicidad. ${ }^{1}$

1 En el presente texto nos referiremos a espacio y territorio desde una perspectiva amplia que envuelve lo físico y lo social. Del mismo modo que Milton Santos, consideramos que ambas nociones constituyen referencias a una construcción social e histórica. 
Este escrito se interesa por revisitar analíticamente Patagonia-Aysén (Chile) desde el discurso social formal, es decir, desde el proceso de producción oficial de conocimiento. ${ }^{2}$ Comprender aquel territorio austral desde esta mirada parece relevante, ya que Patagonia-Aysén ha sido durante todo el siglo xx y lo que va del actual, socialmente proyectada como un espacio cuyo elemento central era el de constituirse en frontera, en límite o área periférica. En ese marco, nos nutrimos de elementos de la hermenéutica filosófica (Gadamer, Ricoeur), de los aportes de la antropología cultural (Geertz, Descola) y la antropología del territorio (Ther, Nates, Skewes, Bello). De igual modo, retomamos una serie de líneas de investigación que en el ámbito de la geografía han venido remarcando la necesidad de reenfocar el problema geográfico desde la producción de saberes y prácticas territoriales (Lindón, 2006; Aliste, 20II; Zusman, 20I3; Núñez, 20II).

\section{El enfoque del problema: geograficidad e historicidad en Patagonia-Aysén}

El territorio de Patagonia-Aysén, ubicado en la zona austral de Chile (figura núm I), ha sido considerado por largas décadas, y hasta la actualidad, como un espacio fronterizo, aislado o periférico. De hecho, en la primera mitad del siglo xx era llamado "las tierras de entremedio" para subrayar su condición de marginalidad con respecto de los territorios nacionales, aunque también su localización norteña respecto a la región magallánica. Aquella mirada está imbuida tanto de la lógica centro-periferia como de la asimilación de la geografía y la materialidad física. Desde nuestro punto de vista, así se olvida un aspecto sustancial: que los territorios resultan de procesos de producción socio-cultural, y por lo tanto tienen temporalidades y finitudes, y sus significados son comprensibles dentro de los marcos sociales desde donde se construyen y difunden. En consecuencia, nuestro interés es explorar esa carencia, tan

2 Es vital, sin embargo, no perder de vista la relevancia del espacio vivido. Dado que comprendemos los espacios fronterizos de modo relacional o intercultural, resulta imposible no considerar el nivel discursivo local, es decir, aquella suerte de racionalidad lugareña que permite realizar el contrapunto entre imaginario geográfico de la nación y la experiencia de la espacialidad singular o local. En la investigación, aquella línea es sustancial, pero el presente artículo no puede ofrecer aún resultados definitivos, ya que nos encontramos desarrollando el trabajo de campo correspondiente. De este modo, como ha sido expuesto, el corazón del texto se referirá a la relación entre el discurso social y el territorio en el caso de Patagonia-Aysén. 
académica y también de amplio arraigo colectivo, por lo que el propósito central del texto es el análisis de la condición fronteriza del territorio de Patagonia-Aysén, en el contexto de la construcción del imaginario geográfico de la nación durante los siglos Xx y XXI.

Esta plataforma de análisis también permite preguntarnos cómo es posible abordar las políticas públicas hacia esos territorios, una vez que se deconstruyen estos discursos tan legitimados. Temas como la identidad, los actores locales o los saberes espaciales, las prácticas y los discursos, permiten identificar nuevas problemáticas e interrogantes pertinentes que emergen al calor de estas otras formas de comprender aquellos territorios.

El punto de partida de este trabajo reconoce que

Figura NúM, I

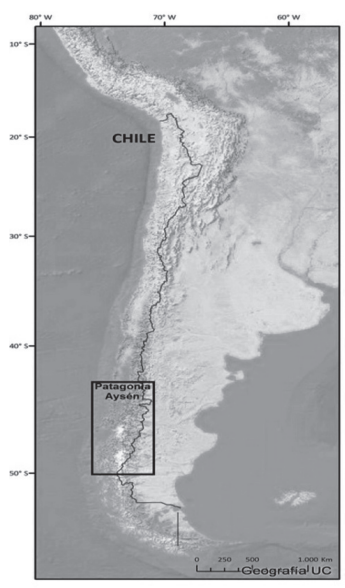

Fuente: Elaboración propia. la posición fronteriza y periférica del territorio de Patagonia-Aysén no está dada por su aislamiento físico, lo que ha sido la "verdad" manejada por la geografía física clásica, ni tampoco deriva de una deficiente inserción en el territorio nacional, lo que resultaría más afín a la geografía política y económica tradicional. Ambas lecturas se basan en un punto de vista centro-periferia, desde donde Patagonia-Aysén es encasillada en la noción de una zona de excepción, una frontera interior. Estas dos lecturas (la propia de la geografía física y la generada en la geografía política clásica) toman su sentido con relación a la escala nacional, que es representada en términos de homogeneidad, uniformidad, conexión e integración. Esa concepción del territorio de escala nacional y su frontera interna se sostienen en un imaginario que no ha sido lo suficientemente analizado de manera crítica. ${ }^{3}$

En contraposición con estas ideas instauradas, en este texto proponemos acercarnos al territorio de Patagonia-Aysén sin reducirlo ni a su condición natural o al carácter de territorio periférico, más bien exploramos la producción de sentido

3 Como ha sido estudiado, el proceso de racionalización y control territorial de Chile que fue definiendo una espacialidad más compacta y homogénea, surgió desde la ilustración borbónica y sirvió sustancialmente, ya en pleno siglo xix, a los intereses de la configuración de los territorios nacionales. En ambas instancias se fue definiendo una geografía nacional que acabó por fijar el sentido de un territorio integrado a la modernidad. $\mathrm{Al}$ respecto, Núnez (2009 y 2013). 
histórico-geográfica que lo fue constituyendo en un territorio periférico. Aquel planteamiento se sustenta en la siguiente pregunta: ${ }_{i}$ Es posible que la supuesta condición fronteriza o periférica de Patagonia-Aysén se funde sólo en criterios físicos o políticos, invisibilizando los marcos discursivos que han enunciado y objetivado tal posición fronteriza? Desde esta perspectiva, comprender e indagar en la condición fronteriza requiere de la revisión de los procesos socio-culturales que han "fronterizado" a Patagonia-Aysén. Por ello, se requiere de la contextualización del problema en la producción de un imaginario geográfico de escala nacional. Y ello implica asumir que el espacio es, ontológicamente hablando, temporalidad. ${ }^{4}$

Considerar la cuestión es estos términos genera cambios metodológicos relevantes respecto a los enfoques más frecuentes. Entre otros, así resulta que Patagonia-Aysén no puede analizarse solo como un espacio objetivo o en su materialidad, como ha sido característico considerarla hasta el día de hoy. Se considera a este territorio como el emergente geográfico de ciertas identidades sociales, tanto locales como nacionales. Por lo mismo, en el estudio de la condición fronteriza de Patagonia-Aysén es imposible pasar por alto los procesos de producción de representaciones geográficas del resto de la nación. Para revisar ello resulta necesario considerar las distintas configuraciones del sentido de lo fronterizo de Patagonia-Aysén, prestando atención tanto a los agentes estructurales y sus prácticas discursivas (Estado), como también a los agentes locales, que en una relación intercultural con la estructura normativa del Estado van asimilando su condición fronteriza que les es impuesta discursivamente.

Este punto de vista concibe la identidad, no como algo dado, estático y único, sino en su pluralidad y constante reconfiguración. La diversidad de la identidad no solo deriva de su construcción sociopolítica, sino también de la existencia de otros saberes, de otras prácticas, que sin ser parte de la estructura dominante del poder (como el Estado), adquieren protagonismo. Por lo mismo, uno de los desafíos que enfrentamos al abordar estas problemáticas radica en la necesidad de visibilizarlos. Lejos de idealizar "lo local", descifrar las identidades particulares deviene una necesi-

4 Sobre el punto nos parece que el pensamiento de Eric Dardel ha sido crucial, aunque sin duda también el de Bachelard. La existencia fija un ser desde una radical temporalidad, pero a su vez el ser se desenvuelve en la tierra, es decir, se define también desde una radical geograficidad. Preguntamos entonces: ¿Cómo explicarnos la tierra si nuestro sentido de tierra ya nos envuelve? En esta línea Dardel expone: "El hombre busca la Tierra, la espera y la llama con todo su ser. Incluso antes de haberla encontrado, la presiente y la reconoce... Así, lo que el hombre busca en la Tierra es un rostro, una cierta acogida" (2013, 106) 
dad para comprender e investigar los asuntos geográficos. Desde esta perspectiva, en el caso de Patagonia-Aysén las identidades australes, por llamarlas de algún modo, no son ajenas a la fijación del sentido patagónico de su "morada".

La propuesta, entonces, cuestiona la tradicional fórmula de estudio de este territorio desde un supuesto centro y una pretendida periferia. Se relativiza así esta fórmula en cuanto a su valor y la potencialidad de interpretación con la que se va significando aquellas tierras. En cierto modo, nos interesa concebir a la "periferia como un centro en sí mismo", cuyo sentido geográfico es el resultado de un diálogo de saberes entre el centro y la propia periferia, aunque con una desigualdad de fuerzas que no debería pasarse por alto.

En el proceso de producción social de la imagen de Patagonia-Aysén surgen diversos lenguajes espaciales desde donde se expresan territorializaciones y re-territorializaciones, en un juego tan dinámico como cargado de concepciones geográficas. Diversos mecanismos o fórmulas de integración y homogenización fueron y son desplegados como plataformas de la imagen de un desarrollo que "está por llegar". Así, por ejemplo, desde inicios del siglo xx se han producido imaginarios para los que lo central era la explotación y roce de los bosques, hasta aquellos otros discursos más actuales en los cuales la idea de la protección y conservación de los bosques ha girado al aspecto nodal. ${ }^{6}$ Aquellas configuraciones, lejos de ser abstractas, impactan en el modo como comprendemos el mundo. Como ha expresado Jacques Lévy (2006) de manera muy elocuente: "Inventar el espacio, para leer el mundo".

\section{Las fronteras y el espacio geográfico, una tradición mutable: el estudio de las fronteras en la geografía clásica}

En la geografía, toda referencia a las fronteras remite a la relación directa entre un espacio y su dimensión política, es decir, las fronteras son concebidas en términos administrativos, suponen líneas que sirven para separar un área geográfica de otra. Su sentido de límite lineal y su vínculo con las fronteras nacionales es lo que domina en la memoria colectiva (Grimson, 20II; Núñez, 2013b). Por otra parte, si se habla

5 Confróntese con Grimson (20II) y Contreras-Ibáñez y Saldívar (2006).

6 Hasta no hace muchos años, el roce (en otras latitudes denominada "roza") era una práctica masiva en la zona, avalada y propiciada por el Estado desde la década de I930, e implicaba la quema de enormes paños de bosques, acción necesaria para "abrir" territorios a la ganadería. El bosque, desde aquella comprensión, era un estorbo para "el desarrollo". 
de fronteras interiores, sigue predominando la interpretación política y su abordaje netamente geopolítico. El énfasis en la escala nacional y la acción pública remite a territorios que deben ser incorporados a la nación, identificando sus carencias y problemas, que los hacen vulnerables para las miradas centralistas. En Chile, aún actualmente, el estudio de las fronteras, internas y nacionales, aún se sigue visualizado desde este tipo de posturas, es decir, desde una geografía política tradicional que se posiciona en los argumentos y prácticas territoriales del Estado y, por lo mismo, todo se sigue tamizando por aquella geografía política que privilegió la dictadura militar chilena (1973-1989). Estas concepciones de la frontera terminaron siendo un instrumento de poder del Estado, con marcado acento normativo, además de resultar útiles en la institucionalización del territorio-nación (Nogué, 200I; Laurín, 2013).

De este modo, el centro del debate y análisis acerca de Patagonia-Aysén ha estado dominado por la idea de integrar, conectar e incorporar, como necesidades insoslayables, vastas áreas al conjunto de la nación a fin de superar los límites territoriales, que separan un área pensada como marginal de otra, que se reconoce como integrada. En otros términos, estas ideas y discursos de cuño nacional, legitiman la integración de áreas al Estado-nación. ${ }^{7}$

Asimismo, durante largo tiempo otros tantos estudios de frontera se han sustentado sobre la base de una geografía física, que únicamente vincula el espacio geográfico con su materialidad. Así, han considerado al espacio algo objetivo, sin mayor valorización o atención sobre los procesos de producción del sentido o significación de dicho espacio (Lindón, 20I2). Como hemos venido resaltando, el espacio, según el paradigma iniciado en el siglo xIx, ha mantenido la impronta de lo inerte, lo estable, lo fijo, es decir, una "naturaleza muerta" (Foucault 1967; Lindón, 2012; Nogué, 2006; Zusman 2013). En consecuencia, ha sido también en el ámbito de la geografía física

7 Al respecto, el caso de la Araucanía en Chile ha sido emblemático. A su ocupación hacia fines del siglo xix se le denominó -hasta el día de hoy en numerosos textos escolaresPacificación de la Araucanía, para justificar el sometimiento de los mapuches tras los levantamientos ocurridos en 1874 y I88I contra las tropas chilenas que avanzaban ocupando sus territorios. La ideología evolucionista - muy en boga en la época, fundada en la apropiación de algunas ideas de Charles Darwin- justificaba y animaba la ocupación del país mapuche, precisamente al proyectarlo como sociedades en el estadio de "barbarie" respecto de la "otra" sociedad "civilizada". A partir de aquel discurso social se visibilizó un territorio que se asumía como no civilizado, "fuera de la historia", que funcionaba alejado de los valores universales del progreso y la Historia y, en consecuencia, alejado del sistema-mundo occidental, pero cuyo espacio contenía tierras cultivables y bosques explotables. 
donde se han buscado respuestas a muchas de las preguntas surgidas en torno a problemas territoriales periféricos o fronterizos, mirada nuevamente asentada en la óptica central. Desde esta perspectiva, ha imperado el argumento según el cual el aislamiento geográfico de las zonas fronterizas se resuelve terminando con la separación física entre las zonas integradas y las desintegradas o desconectadas.

\section{La noción de frontera y de espacio geográfico en discusión: las fronteras desde el espacio socialmente construido}

En los últimos años, especialmente desde la década de los noventa del siglo $\mathrm{xx}$, los estudios fronterizos contemporáneos ya no han aceptado como suficiente el análisis geopolítico limitado a la órbita del Estado central, ni el estudio del espacio geográfico como exclusiva materialidad. Nuevas preguntas y puntos de vista han formulado otros enfoques capaces de problematizar tanto aquella definición de espacio geográfico, como la de fronteras entendidas como algo más que límites, áreas de excepción o zonas separadas y diferentes (Chávez, 20II; Grimson, 2000, 20II; Ther, 2012).

En los últimos años, los estudios fronterizos no solo han rechazado la lectura exclusivamente política o física, sino que han ampliado el panorama en un diálogo abierto con las otras ciencias sociales (Zusman, 1999; García Canclini, 2005; Hevilla, 2007; Grimson, 2000, 20II; Núñez, 2013b). Sin desconocer la visión de frontera como una línea o un área que marca diferencias de un lado y otro, los estudios de frontera se han interesado en una comprensión social y cultural de aquellos territorios. En otras palabras, se ha ido legitimando la idea de las fronteras como zonas porosas donde la interculturalidad es lo relevante. De esta suerte, el énfasis ya no está puesto en las diferencias entre un "nosotros" y un "ellos" (Said, 20I0), ni tampoco en evidenciar la labor de un Estado que busca demarcar políticamente la zona fronteriza como excepción o anomalía, donde el panorama recurrente es la necesidad de su integración, incorporación, homogenización o su institucionalización en relación al resto de la nación.

Por el contrario, lo que se ha empezado valorizar es precisamente el sentido relacional, vinculante y de construcción recíproca de las zonas fronterizas. De este modo las representaciones que los sujetos sociales hacen del territorio, sean ellas estatales o locales, se tornan fundamentales para comprender los procesos de construcción territorial y sus formas de apropiación (Bello, 20II). En otras palabras, es relevante prestar atención tanto a lo vivido (las prácticas y los agentes locales), como a lo normado (los discursos, la estructura, el Estado hegemónico) (Ther, 
20I2; Aliste, 20II), en una relación dialéctica que termina por producir o construir la "condición fronteriza".

Observamos, por lo tanto, el espacio geográfico fronterizo como construcción social cuyo significado solo es comprensible y visible desde discursos y prácticas que lo fronterizan, es decir, desde aquél proceso de significación territorial que lo va representando como una condición excepcional o diferente. En otras palabras, nuestra lectura se posiciona en la territorialización del discurso social, mirada o cosmovisión que en sí envuelve el lenguaje geográfico que busca definir. ${ }^{8}$

Arribamos así a la comprensión del espacio fronterizo desde "lo social", desde el lenguaje cultural que lo expone y manifiesta, así como desde la construcción de imaginarios geográficos que lejos de integrar la inmaterialidad, nos imponen territorialidades, a partir de las cuales los grupos fijan sentidos y significaciones espaciales (Lindón, 2012). Desde aquella perspectiva, como permite plantear Clifford (1995: 30), "la identidad-fronteriza es coyuntural, impuesta y no es esencial".

En nuestra aproximación, tanto las fronteras nacionales como las internas de la nación pueden ser entendidas como espacialidades de una memoria social que fija acuerdos de sentido en torno a dichos espacios donde, más allá de los límites territoriales (internos o binacionales), existe una dialéctica de producción y reproducción de significados que circulan entre el grupo que habita el lugar fronterizo y el que incide en sus destinos (Pech, 2008). Esta relación comunicativa y vinculante muestra un proceso de reproducción social, desde el cual es factible visualizar las diversas formas con que el territorio va adquiriendo determinados sentidos, valores, representaciones, definiciones y significados de tipo fronterizo. En otras palabras, en aquel proceso versátil y cambiante es factible identificar la fundación social o sociogénesis de la espacialidad fronteriza.

Este enfoque propuesto resulta clave para explicar la manera en que se construyen las identidades geográficas, entendiendo "lo geográfico" no solo desde la materialidad sino también en su dimensión simbólica (Zusman, 2013). ${ }^{9}$ Como ha destacado Lindón: "La integración de la dimensión de lo imaginario en geografía

8 El punto es importante en el proceso de investigación que llevamos a cabo con los territorios patagónicos, ya que se debe constatar que primero está el lenguaje y después la interpretación. En otras palabras, el lenguaje no vendría a ser lo expresado sino lo que nos expresa. Esto conlleva una situación de fondo y es que el lenguaje es, por tanto, experiencia del mundo (Gadamer, 1999, 526). Así como nuestra conciencia no es a-histórica, tampoco es a-lingüística. El lenguaje, en definitiva, es representarse (Gadamer, 1999, 58I).

9 En este contexto, la identidad no es pura, es siempre contaminada, híbrida, mixta, relacional. 
responde a la necesidad de asumir que el espacio no se reduce a la simple materialidad" (20I2: 15). El análisis de los territorios fronterizos requiere del estudio de la territorialización (Santos, 1996; 2000), así como de la identificación del desarrollo de sus particularidades. En otras palabras, es necesario revisar aquella red puntual de conexiones, vínculos y enlaces espacio-temporales y los significados asociados (Jelin, 2004), evaluando críticamente los conceptos de frontera y espacio geográfico patagónico que se han privilegiado desde la plataforma política y física.

\section{Representar el espacio de Patagonia-Aysén: interculturalidad y expresión social}

En el contexto de las representaciones que se han ido dando acerca de Patagonia-Aysén desde inicios del siglo $\mathrm{xx}$, ha predominado la lectura de un territorio concebido como un sujeto ajeno, anormal y extraño, diferente y desconectado, aislado o desintegrado. Aquellas narrativas perduran con fuerza hasta el día de hoy. Han sido, en su conjunto y de manera monolítica, proyectadas desde el centro del poder político. De allí que sea necesario girar la mirada y observar otras perspectivas:

El Estado-nación es una escala territorial que se refiere a un espacio geográfico apropiado, delimitado, controlado y usado por un Estado. Comprender el proceso de constitución de la estructura territorial nacional y sus permanentes transformaciones implica relacionar y ligar los procesos socioespaciales y territoriales que ocurren en esa escala, con los mismos procesos que ocurren en escalas subnacionales (regionales o locales) con una revisión geohistórica periodizada y con su respectiva diferenciación regional (Delgado, 2009: IOI).

De este modo, esto último resulta central para evaluar la supuesta condición fronteriza de aquellos territorios australes. No se debe perder de vista "el sistema de relaciones de sentido que identifica diferencias, contrastes y comparaciones" (García Canclini, 2004: 20), a fin de comprender y visualizar por el proceso de producción de aquella categoría, y también su particularidad en su interculturalidad estatal/local.

En efecto, la condición fronteriza a que hemos venido haciendo mención es, en el fondo, historicidad y formación discursiva (Foucault, 199I, 1997). Por lo mismo, el resultado de la combinación de una visión del poder (institucionalización del espacio) y de las prácticas sociales locales. En ambos casos, el sujeto social -y su espacialidad- no es solo el Estado, es también el habitante local, que se readapta y redefine 
a partir de un espacio geográfico reinventado y resignificado, lo que implica, como expresamos, deslizamientos de sentido.

Ahora bien, como el mismo Foucault ha observado, el poder estatal no es abstracto, es racionalizado por grupos a partir de las prácticas de gobernar: "Gobernar un Estado será, pues, poner en práctica la economía, una economía a nivel de todo el Estado, es decir, tener con respecto a los habitantes, a las riquezas, a las conductas de todos y cada uno, una forma de vigilancia, de control, no menos atenta que la del padre de familia sobre todos los miembros de la casa y sus bienes" (Foucault, 1999: 182). Desde esta perspectiva, la constitución de una espacialidad fronteriza, entonces, será la tarea ineludible a fin de "cercar" el hábitat de la familia-nación. ${ }^{10}$

El territorio de Patagonia-Aysén, en aquel marco, ha tenido un dominio interpretativo estado-céntrico, con una serie de políticas y lineamientos que han ido, como hemos expuesto, fronterizando el territorio patagónico. De allí que junto con constatar aquella producción social del espacio desde aquel centro político y social, también resulte un desafío la posibilidad de comprender la periferia como centro (Sahlins, 1989; Grimson, 2000), con una dialéctica que rescata lenguajes y voces sociales de ambas partes. Aquello permite resaltar los rasgos de particularidad que adquiere la relación entre el espacio y la fijación de su sentido fronterizo por parte de agentes externos (Baeza 2007, Grimson, 2000, 201I):"El concepto de fronterización alude a los procesos históricos en los cuales intervienen los poderes centrales y las

10 Hemos planteado (Núñez, 2009) que la producción de un imaginario moderno de la nación chilena implicó el desenvolvimiento de numerosos dispositivos de control territorial. Entre otros, (I) el control de los "espacios vacíos", es decir, la creación de nuevos asentamientos y espacios urbanizados con el fin de controlar distancias $y$, a través de ellas, el territorio; (2) la búsqueda y acumulación de información, que en el fondo fue una continuación de los cuestionarios borbónicos, en lo que podría denominarse un verdadero catastro de los bienes existentes en el territorio asociado a la nueva nación; (3) la exploración científica de nuevos territorios y su incorporación al marco territorial que definía a la nueva nación; (4) la supremacía simbólica de la ciudad sobre lo rural, lo que, como en otras latitudes, colaboró a fijar en lo urbano el dominio de un discurso hegemónico; (5) la conformación de una historia nacional que diese sentido a sus habitantes, una perspectiva que generó mitos y héroes comunes, impactando en la memoria de la nación y en su necesidad de mirar un futuro, fruto de su propia tradición; (6) la materialización del telégrafo, que colaboró a minimizar distancias; (7) la materialización del correo, que hizo que la temporalidad sufriera cambios de valorización y sentido; (8) mejoramientos de caminos y puentes, y (9) la implementación del ferrocarril, tal vez el más simbólico de los dispositivos de control. 
poblaciones locales, construcción que es constantemente disputada, reestructurada y resignificada" (Baeza, 2007: 20).

El espacio de Patagonia-Aysén, utilizando la línea argumentativa de Santos (2000), ha sido geografizado de manera fronteriza y periférica por agentes asentados en la estatalidad, que han ido moldeando su devenir y respecto de los cuales las comunidades locales se han ido adaptando y asumiendo ese horizonte geográfco-fronterizo como suyo, por cierto, en algunos casos con resistencias y/o tensión. El desplazamiento del significado en el caso de estudio tiene que ver con temporalidades que implican territorializaciones y re-territorializaciones de la condición fronteriza, donde se fue produciendo una programación y reprogramación en el marco de nuevas y renovadas convenciones colectivas, sean éstas centrales o periféricas.

En definitiva, la "geografía" de Patagonia-Aysén no es un asunto dado sino más bien un devenir. Ese horizonte espacial incorpora la expresión geográfica de las identidades sociales y culturales (Crosgrove, 2002), dando paso a significados que se fijan como definitivos, pero, como veremos en el siguiente apartado, se pierden en la memoria de una historia que, en cierto modo, le perteneció a otros. Para el Estado y las cosmovisiones centro-periferia, por ejemplo, esos territorios requerirán con urgencia soluciones que lleven a los habitantes a sentirse conectados o integrados. Para atender este asunto se despliegan acciones y dispositivos encaminados a materializar aquel imaginario. Los habitantes locales -normalmente llamados "colonos" o "pioneros"- lo visualizan así, como un mundo "por venir", un nuevo comienzo y se sienten tan ajenos como, a la vez, insertos en una espacialidad más amplia que pueden denominar "patria" o nación. ${ }^{11}$

Son aquellas identidades sociales las que elaboran y ejecutan, a través de dinámicas, conflictos, acuerdos, resistencias, en un proceso que lleva consigo cierta temporalidad, y una espacialidad cuya característica central es su condición fronteriza.

11 En una investigación previa sobre la zona, se pudo comprobar que un porcentaje sustancial de habitantes de valles aislados de Patagonia-Aysén "no se sienten ni perciben aislados" y que "los aislados", según ellos, serían los habitantes del resto del país (Arenas, 20II). Incluso van más allá cuando manifiestan que su "aislamiento" es político en tanto no pueden tomar decisiones ni afectarlas. 


\section{Un territorio construido como frontera: Patagonia-Aysén desde los procesos de territorialización del discurso social}

Aunque las periodizaciones siempre son frágiles, también pueden resultar pertinentes a fin de visualizar el desplazamiento del sentido y el cambio de la territorialización. A su vez, también ayudan en este caso para no perder de vista que gran parte del sentido geográfico - que en última instancia se transforma, en el emergente de la memoria colectiva - tiene su génesis en el contexto de una producción de sentido territorial de escala nacional.

De este modo, identificamos un primer momento en el tránsito del siglo xIx al $\mathrm{xx}$, cuando el espacio patagónico de Aysén es definido como "las tierras de entremedio" (Bandieri, 20II: 220), en el contexto de la representación geográfica nacional. Y así fue posible denotar un área poco o nada integrada al imaginario territorial de la nación. Aquel imaginario indicaba que Chile cubría todo el norte de Patagonia-Aysén y también la zona más austral de Magallanes, ocupada e incorporada durante el siglo XIX. Desde esta perspectiva, Patagonia-Aysén era concebida como un espacio vacío entre dos "certezas geográficas". En cierto modo, era visto como un horizonte territorial a-histórico, desconectado del devenir de la modernidad y con ello de los referentes tanto de la identidad nacional como de los caminos de la razón. ${ }^{12}$

Para este tiempo, algunas características nos permiten comprender la geograficidad ligada a los imaginarios de Patagonia-Aysén. En primer lugar, es atendible la presencia activa de pobladores chilenos que se instalan en los márgenes de la cordillera patagónica impulsados (o expulsados) por el gobierno argentino en el proceso de nacionalización de las tierras patagónicas "argentinas. ${ }^{13}$ Estos campesinos

12 Razón e Historia han conformado una dupla surgida al alero del idealismo hegeliano que ha venido a definir una conciencia histórica desde donde es factible observar el desarrollo de un tiempo lineal y teleológico. En contraposición, durante el siglo xx se ha dado impulso a una conciencia hermenéutica que no solo ha cuestionado las bases metafísicas de aquella comprensión de la historia sino que ha llevado a fijar el conocimiento como despliegue finito y móvil, es decir, como acontecer. En otras palabras, comprendemos lo ya comprendido y en esa fusión de horizontes de pasado-presente van surgiendo nuevas interpretaciones, renovados lenguajes. Desde nuestro punto de vista, el punto es muy interesante y provocador, porque el futuro no estaría "adelante" sino precisamente en la tradición (Gadamer, 1999).

13 Argentina como tal no existía en las pampas australes, incluso hoy es factible observar un lenguaje sociocultural distinto al de latitudes porteñas (Buenos Aires), pero sin 
encontraron en esas tierras una respuesta a su improvisado nomadismo. Este proceso espontáneo dio origen a la serie de asentamientos y pueblos que en la actualidad definen los límites de la frontera política en el área. Por otra parte, aunque con una timidez llamativa, hubo un despliegue de agentes del Estado que exploraron y buscaron naturalizar algunos territorios australes para la nación, legitimando una tenue presencia estatal (Navarro Floria, 2007; Baeza, 2007).

A su vez, en una práctica paradigmática para la época, pero que dejaba traslucir la existencia de un poder político instalado en la capital de la nación, el Estado traspasó a empresas privadas ganaderas la responsabilidad de ocupar y explotar las alejadas tierras de Aysén, en una lógica de desarrollo que "posibilitó nuevos sentidos y nuevas posibilidades de las prácticas espaciales" (Harvey, 2008). Estas empresas ganaderas fracasaron en su mayoría, algunas incluso ni siquiera se hicieron presentes en la zona, pero son importantes para el análisis porque inauguraron la imagen de un territorio ganadero, al estilo del Oeste americano, en un área colmada de densos bosques fríos, con niveles de precipitación muy elevados (Figura núm.2).

\section{Figura NúM. 2}

Empleados de la Sociedad Industrial Aysén (S.I.A.) vadeando el río Simpson cerca de Coybaique, 1920.

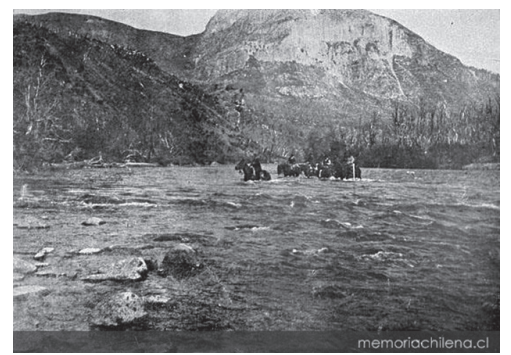

Fuente: Biblioteca Nacional, Chile.

duda se encontraba en pleno proceso la definición de los Territorios Nacionales, lo que impactaba en la implantación de límites y en la planificación de lo que debía ser y entenderse por "Argentina". Dos excelentes libros para comprender el problema son: Silvestri, Graciela (20II). El lugar común. Una historia de las figuras de paisaje en el Río de la Plata. Buenos Aires, Edhasa y Navarro Floria, Pedro (2007). Los paisajes del progreso. La resignificación de la Patagonia Norte, 1880-1916. Neuquén, EDuco, Universidad Nacional de Comahue. 
Por último, nos encontramos con un territorio cuyo sentido de pertenencia era definido por el vínculo con las pampas argentinas, más que con el Océano Pacífico o con el "norte" chileno. Ello hizo forjar un escenario donde la frontera era la integración patagónica y la cordillera libre (Lacoste, 2003).

Un segundo y amplio momento es el que comienza durante la década de 1920. Se trata de una etapa fundacional, con políticas de desarrollo regional que buscan avanzar de modo más directo en la chilenización de la zona. Se trata de una etapa de re-territorialización del discurso social.

En este largo período, cuyo término coincide con la irrupción de la dictadura militar en 1973, el paisaje es dominado, discursivamente, por la idea de frontera. Es el tiempo de la institucionalización de Patagonia-Aysén, con políticas de desarrollo marcadas por el protagonismo del "colono", como la figura que comienza a delinear el sentido patriótico de vivir en aquellas alejadas zonas. De este modo, el mito fundacional de la región con el esfuerzo y la chilenidad se impone a la lógica de una zona proyectada como "tierras de entremedio". En la práctica, Patagonia-Aysén sigue tan ajena a la nación como antes, pero el discurso político de integración se instala con fuerza por la vía de los "pioneros" o "colonos", que resultaron ser una suerte de agentes de avanzada para hacer confluir el centro y la periferia. Un aspecto digno de destacar es la urgencia con que el Estado les exige a los colonos, a través de contratos, el despeje de los territorios. Ello no solo se refiere a la implantación de la "vocación territorial ganadera" para la zona, sino que también lleva consigo la búsqueda del triunfo de la civilización sobre la irracionalidad y el caos, que implicaban los bosques salvajes e impenetrables (AMTC, 1944).

Esta fase de resignificación territorial resultará clave porque es en estos años cuando se fija en el imaginario geográfico de la nación, el horizonte del "paisaje fronterizo" de Aysén. Así es cuando se institucionaliza la idea de este territorio como zona de excepción. El imaginario geográfico atribuido a la zona aún remite a la condición de área marginal respecto de "Chile". Sin embargo, aquella chilenidad territorial, aunque lejana, será el marco social que comienza a configurar lo local. Incluso, hacia el fin de la siguiente fase, cuando los colonos viajaban al norte de Patagonia-Aysén decían "voy para Chile".

14 Aquel fue el relato recurrente de los colonos. Los testimonios sobre la lejanía de "Chile" son reconocidos en base a diversos encuentros con pobladores locales que de modo esporádico se han ido llevado a cabo por los autores en la zona norte de la región de Patagonia-Aysén desde 1990 a la fecha. 


\section{Figura NÚM 3}

Colonos en Patagonia-Aysén hacia 1935.

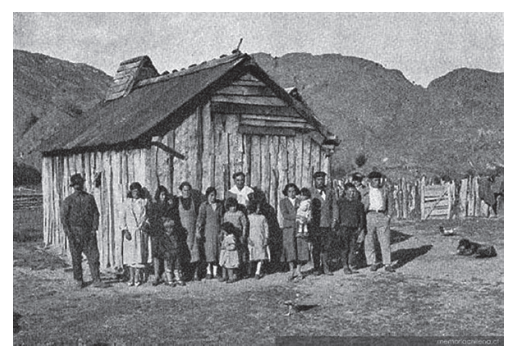

Fuente: Biblioteca Nacional, Chile.

Con el arribo de la dictadura militar en 1973, Patagonia-Aysén vive la reconfiguración de un nuevo proceso de territorialización, que se caracteriza por la presencia estatal decidida y agresiva, dominada por un marcado carácter geopolítico, bajo la impronta militar que se impuso por aquellos años.

Este es un tiempo muy interesante para comprender la zona desde la geografía social que seguimos. En efecto, en esta fase el territorio de Patagonia-Aysén se resignifica desde la mirada de la frontera como conquista, como un espacio que debe ser integrado para que se alcance la civilización y el progreso, tal como lo planteara Turner (1982) con relación a la colonización del Oeste americano (Hevilla, I998; Zusman, 1999). La condición fronteriza, así, se agudiza. Y ello se concreta en la activa presencia estatal. De hecho, es el tiempo en que Aysén es declarada oficialmente, por parte del Estado nacional, como "Frontera Interior". Contradictoriamente con lo formulado por los lineamientos económicos de esos años en torno al liberalismo económico, estas décadas se caracterizan por una fuerte y planificada presencia estatal, con un activo proceso de racionalización y control del espacio, que se vio reflejado, entre otros aspectos, en la construcción de la Carretera Austral, que vino a "unir" el territorio en sentido norte-sur, es decir, el mismo sentido forjado por "Chile" en los siglos anteriores. ${ }^{15}$ Aunque aquella carretera no era más que una senda de penetración, el nombre de "Carretera" denotó la impronta simbólica de su construcción. En

${ }^{15}$ El estudio de una espacialidad oeste-este en Chile -en lo que se ha llamado El país de las cuencas- y la invención de la homogeneidad norte-sur en Núnez (2012; 2013). Es interesante constatar cómo el imaginario geográfico "vertical" o norte-sur de escala nacional impactó en la producción de nuevas territorialidades para la patagonia chilena. 
forma paralela, se crearon numerosos Parques Nacionales, también símbolos del interés estatal de integrar aquellos territorios a la nación chilena y controlarlos. ${ }^{16}$

A partir de esas estrategias comenzaba a desarrollarse el discurso conservacionista y del "fin de mundo", que luego resultaría funcional para la construcción del imaginario turístico, que recién madurará en la siguiente etapa (MBN, 1984).

En efecto, hacia 1990 y en un proceso aún en curso, la condición fronteriza de Patagonia-Aysén vuelve a modificar su sentido territorial, iniciándose la valorización de aquella espacialidad específica en base a cierto consenso conservacionista y turístico.

El proceso económico dominante de liberalización, de escala nacional, iniciado en 1973, se prolonga más allá del final de la dictadura y se extiende a la región que analizamos, dando paso a una intensa especulación con la tierra y a una inusitada valorización de la misma por y para el turismo y la protección de la naturaleza. En cierto modo, parafraseando a Doreen Massey, se puede decir que Patagonia-Aysén adquiere un sentido global desde su racionalidad lugareña. Todo ello genera una tensión inédita en la relación centro-periferia, en tanto la incorporación e integración de aquellas lejanas tierras a la nación deberá hacerse bajo la lógica de cierta racionalidad conservacionista, que busca dejar a la "periferia como periferia", como el escenario de un "paraíso verde". La biodiversidad y el turismo de intereses especiales concentra el lenguaje social, cual paradigma, marcando una renovada geograficidad de Patagonia-Aysén (Gore, Aysén, 1994).

La conjunción de lo anterior ha llevado a que estos nuevos marcos socio-discursivos en torno a la conservación y la protección de la naturaleza justifiquen lo que hemos denominado "una renovada colonización", ahora con un colono cuya presencia física no es vital. En efecto, un nuevo tipo de colonización que posee sus bases y sustento en lo que Harvey ha denominado la renta del monopolio, en tanto que "su búsqueda conduce al capital mundial a valorizar iniciativas locales específicas [...], a la valorización de la singularidad, la autenticidad, la particularidad, la originalidad y cualquier otra dimensión de la vida social incongruente con la homogeneidad presupuesta por la producción de mercancías" (2007: 433).

${ }^{16} \mathrm{Al}$ respecto, hemos tenido en cuenta el trabajo de Beserra, E.M. (20II). "La nacionalización de las fronteras patagónicas: los parques nacionales como herramienta estatal de ocupación e integración territorial". En Valverde, S.; Maragliano, G.; Impemba, M. Y Trentini, F. Procesos históricos, transformaciones sociales y construcciones de frontera. Aproximaciones a las relaciones interétnicas. Estudios sobre Norpatagonia, Argentina, Labrador, Canadá. Buenos Aires, Universidad de Buenos Aires. 
En la actualidad, Patagonia-Aysén convive con la lógica de ser una "reserva de vida" en el fin de mundo, que debe ser protegida y resguardada, con una activa y creciente especulación de la propiedad de la tierra, donde los capitales mundiales arriban a la zona interesados en reforzar aquella condición fronteriza. ${ }^{17}$

\section{Conclusiones}

Los procesos descritos no son rígidos, por lo que junto a la frontera física se desarrolla la frontera discursiva. Así, la construcción de imaginarios territoriales que a lo largo del siglo xx y lo que va del xxI, se han ido generando en torno a Patagonia-Aysén, nos permite descifrar la existencia finita y cambiante de los procesos de construcción de sentido territorial, surgidos de los discursos sociales. Indagar en la territorialidad de Patagonia-Aysén es una forma de comprender la proyección de imágenes con que la sociedad se reconoce geográficamente.

Aquella hermenéutica del territorio, en distintos tiempos históricos, ha impactado en la memoria colectiva, que en último término ha ido definiendo a la zona como un territorio carente de progreso y desarrollo, cuyos problemas se solucionarían con la integración y conectividad. La geografía ha sido institucionalizada al enfatizar solo los componentes físicos y geopolíticos de la zona, sin prestar atención a los marcos discursivos desde donde surge la particular imagen geográfica.

Desde esta perspectiva, emerge la pregunta: ¿en qué medida el sentido espacial de Patagonia-Aysén como periferia, es el resultado de imaginarios geográficos de la escala nacional? Así, en la actualidad es posible seguir visualizando imágenes e imaginarios que se configuran de manera ajena al espacio vivido por sus habitantes. Numerosos colonos o "pioneros" se han visto llevados a adecuarse a labores de tipo turístico, o de protección de la naturaleza como ideas impuestas, pero ajenas a su memoria y morada territorial, comúnmente asociada a la imagen ganadera de esta tierra. Se adaptan a estas ideas e intentan comprender al bosque como algo sagrado y recuerdan, como una memoria casi perdida, el tiempo en que el bosque era solo "mala yerba" frente a las tierras con ganado. Ni antes ni ahora, el territorio solo era "ganadero" o "conservacionista", el territorio es el devenir de geografías ancladas en los sentidos sociales del territorio.

Así, la geografía social permite comprender el territorio de Patagonia-Aysén no ya desde la diferencia, la marginalidad o la excepción (la interpretación centro-pe-

17 El eslogan de la región de Aysén desde 1990 es precisamente "Aysén, Reserva de Vida". 
riferia), sino fundamentalmente desde su relación con el discurso y los saberes geográficos de alcance nacional o binacional (interculturalidad). Así se visibilizan sus particularidades discursivas (visiones del mundo), y emergen nuevas posibilidades de desarrollo y representación socio-espacial para la zona (interpretaciones periferia-centro).

\section{Bibliografía}

Archivo del Ministerio de Tierras y Colonización (AмTC)

1944 Actas de radicación. Santiago de Chile.

Aliste, Enrique

2011 "Territorio y huellas territoriales: una memoria del espacio vivido en el Gran Concepción, Chile", en Desenvolvimento e Meio Ambiente, núm. 23, pp. 25-38.

Aliste, E.y A. Núñez

2013 "Las fronteras del discurso geográfico: el tiempo y el espacio en la investigación social", en Seminario de Doctorado de Ciencias Sociales de la Universidad de Chile. Inédito.

Arenas, F., A. Salazar y A. Núñez (eds.)

20II El aislamiento geográfico: ¿problema u oportunidad? Geolibros, Santiago de Chile.

Baeza, Brígida

2007 Fronteras e identidades en Patagonia central (1885-2007), Prohistoria, Rosario.

Bandieri, S.

20II Historia de la Patagonia, Sudamericana, Buenos Aires.

Bailly, Antoine

2013 "Las fronteras: representaciones, poderes y divisiones territoriales", en A. Núñez, R. Sánchez y F. Arenas (eds.), Fronteras en movimiento e imaginarios geográficos. La cordillera de Los Andes como espacialidad socio-cultural, Geolibros-RIL Editores, Santiago de Chile.

Bello, Álvaro

20IIa Nampülkafe. El viaje de los mapuches de la Araucanía a las pampas argentinas.Territorio, politica y cultura en los siglos XIX y XX, Ediciones UC Temuco, Temuco. 
20Ib "Espacio y territorio en perspectiva antropológica. El caso de los purhépechas de Nurío y Michoacán en México", en cuHso, núm. 2I, pp. 39-6o.

Clifford, James

1995 Dilemas de la cultura, Gedisa, Barcelona.

Contreras-Ibáñez, Carlos y Alicia Saldívar

2006 "Crítica de las identidades desde la Psicología social", en Rocío Rosales, Servando Gutiérrez y José Luis Torres (coords.), La interdisciplina en las Ciencias Sociales, Anthropos, Barcelona, pp. II7-I25

Chávez, M., O. González y M. Ventura (eds.)

2011 Geografía bumana y ciencias sociales. Una relación reexaminada, El Colegio de Michoacán, México.

Dardel, Eric

2013 El Hombre y la Tierra. Naturaleza de la realidad geográfica, Biblioteca Nueva, Madrid.

Delgado, $\mathrm{O}$.

2009 "Geografía y Ciencias Sociales. Una relación reexaminada", en M. Chávez, O. González y M. Ventura (eds.), Geografía bumana y ciencias sociales. Una relación reexaminada, El Colegio de Michoacán, México.

Foucault, Michel

199I Saber y verdad, Ediciones de la Piqueta, Madrid.

1997 La arqueología del saber, Siglo xxi, México.

1999 Obras esenciales: Estrategias de poder, vol. 2, Paidós, Barcelona. Gadamer, Hans G.

I999 Verdad y método, Ediciones Sígueme, Barcelona.

García Canclini, Néstor

1999 La globalización imaginada, Paidós, Buenos Aires.

2005 Culturas hibridas. Estrategias para entrar y salir de la modernidad, Paidós, Buenos Aires.

2004 Diferentes, desiguales y desconectados: mapas de la interculturalidad, Gedisa, Barcelona.

2000 "¿De qué lado estás? Metáforas de la frontera de México-Estados Unidos", en Alejandro Grimson (comp.), Fronteras, naciones e identidades. La periferia como centro, Ediciones Cicuus, Buenos Aires, pp. I39-I52.

Geertz, Clifford

1987 La interpretación de las culturas, Gedisa, Barcelona 
Gobierno Regional de Aysen

1994 Informe final desarrollo sustentable, poblamiento e integración territorial de Aysén, Coyhaique.

Grimson, Alejandro (comp.)

2000 Fronteras, naciones e identidades. La periferia como centro, Ediciones ciccus-La Crujía, Buenos Aires.

Grimson, Alejandro

20II Los límites de la cultura. Crítica de las teorías de la identidad, Siglo xxi, Buenos Aires.

Halbwachs, Maurice

2004 Los marcos sociales de la memoria, Barcelona, Anthropos.

Harvey, David

2007 Espacios del capital. Hacia una geografía crítica, Madrid, Akal.

2008 La condición de la posmodernidad. Investigación sobre los orígenes del cambio cultural, Amorrortu, Buenos Aires.

Hevilla, Cristina

1998 "El estudio de la frontera en América. Una aproximación bibliográfica", en Revista Bibliográfica de Geográfica y Ciencias Sociales, Universidad de Barcelona, núm. 125. <http:/www.ub.es/geocrit/b3w-I25.htm> [agosto de 2013).

2007 "Territorialidades en movimiento: desplazamientos y reconfiguraciones territoriales ante las inversiones extranjeras en ámbitos de frontera", en P. Zusman, C. Lois y H. Castro (comps.), Viajes y geografías, Prometeo Libros, Buenos Aires, pp. 203-224.

Hiernaux, Daniel y Alicia Lindón (dir.) Tratado de geografía bumana, UAm, Anthropos, México.

Jelin, Elizabeth

2004 "Reflexiones (localizadas) sobre el tiempo y el espacio", en Grimson, Alejandro (comp.) La cultura en las crisis latinoamericanas. Clacso Libros. Buenos Aires, pp. 237-247.

Lacoste, $\mathrm{P}$.

2003 La imagen del otro en las relaciones de la Argentina y Chile (1534-2000), Fondo de Cultura Económica de Argentina, Universidad de Santiago de Chile, Instituto de Estudios Avanzados, Buenos Aires.

Laurín, Alicia y Andrés Núñez

2013 "Frontera, globalización y deconstrucción estatal: hacia una geografía política crítica", en M. A. Nicoletti y P. Núñez (comp.), Araucanía-Nor- 
patagonia: la territorialidad en debate. Perspectivas ambientales, culturales, sociales, politicas y económicas, IIDyPca, Universidad Nacional de Río Negro, Bariloche.

Lévy, Jacques

2006 "Actores, , objetos, entornos: inventar el espacio para leer el mundo", en A. Lindón y D. Hiernaux (eds.), Los giros de la geografía bumana. Desafios y horizontes, uam, Anthropos, México.

Lindón, Alicia

2006 "La territorialidad y el significado de la casa: una visión in-disciplinada de la periferia metropolitana", en R. Rosales, S. Gutiérrez y J. Torres (coords.), La interdisciplina en las Ciencias Sociales, uam, Anthropos, México.

Lindón, Alicia; Hiernaux, Daniel (eds.)

2010 Los giros de la Geografía Humana. Desafíos y horizontes. México, uam, Anthropos.

2012 Geografías de lo imaginario. México, uAM, Anthropos.

Navarro, Floria P. (coord.)

2007 Paisajes del progreso. La re-significación de la Patagonia Norte, 1880-1916, Centro de Estudios Patagónicos, Universidad Nacional de Comahue, Neuquén.

Nogué, Joan y Joan Vicente Rufi

200I Geopolitica, identidad y globalización, Ariel, Barcelona.

Nogué, Joan y Juan Romero (eds.)

2006 Las otras geografías, Tirant lo Blanch, Valencia.

Ministerio de Bienes Nacionales (MBN)

I984 Plan de Poblamiento Región Austral. Cartilla Ecológica del Colono, División de Colonización., Santiago de Chile.

Núñez, A.

2009 La Formación y consolidación de la representación moderna del territorio en Chile: 1700-1900, tesis para optar al grado de Doctor en Historia. Instituto de Historia, Universidad Católica de Chile.

201 "Territorios fronterizos, territorios aislados: conceptos dinámicos de construcción histórica (procesos de significación)", en F. Arenas, A. Salazar y A. Núñez (eds.), El aislamiento geográfico en Aysén: iproblema u oportunidad? Santiago, Geolibros.

2012 "El país de las cuencas: fronteras en movimiento e imaginarios territoriales en la construcción de la nación. Chile, siglos XVIII-XIX”, XII 
Coloquio Internacional de Geocrítica (Bogotá, 7-II de mayo de 20I2). [En línea]. <http://www.ub.edu/geocrit/coloquio2or2/actas/o2-ANunez.pdf $>$.

2013a "Definiendo una geografía para la nación: la re-significación territorial de Chile, siglos xviri-xıx", en Bonastra, Q.y G. Jori (eds.), Poder, territorialización y socialización en los orígenes del Estado-nación, Icaria, Barcelona.

2013b "Geografía, historicidad y hermenéutica. Conversaciones sobre Geografía con el geógrafo francés Dr. Alain Musset”, dossier de Geografía histórica, número especial editado por A. Núñez, en Revista de Geografía Norte Grande, núm. 54, Instituto de Geografía, Universidad Católica de Chile.

Núnez, A., F. Arenas y A. Salazar

20II "El aislamiento geográfico: un asunto de perspectivas", en Arenas, F; Salazar, A.; Núñez, A. (eds.)(20II). El aislamiento geográfico: iproblema u oportunidad? Santiago, Geolibros.

Núñez, R. Sánchez y F. Arenas

2013 Fronteras en movimiento e imaginarios geográficos. La cordillera de Los Andes como espacialidad sociocultural, Geolibros-RIL Editores, Santiago de Chile.

Pech, C., M. Rizo y V. Romeu

2009 "El habitus y la intersubjetividad como conceptos clave para la comprensión de las fronteras internas. Un acercamiento desde las propuestas teóricas de Bourdieu y Schütz", en Frontera Norte, vol. 2I, núm. 4I,

Sahlins, Peter pp. 33-52.

I989 Boundaries. The making of France and Spain in the Pyrenees, University of California Press, Los Angeles-Oxford.

\section{Said, Edward}

2010 Orientalismo, Debolsillo, Barcelona.

Santos, Milton

1996 De la totalidad al lugar, Oikos-taus, Barcelona.

2000 La naturaleza del espacio. Técnica y tiempo. Razón y emoción, Ariel Geografía, Barcelona.

2012 "Antropología del territorio", Polis, vol. II, núm. 32, pp. 492-510. 
Turner, F. J.

I982 La frontera en la bistoria americana (1893), Universidad Autónoma de Centroamérica, San José, Costa Rica.

Zusman, Perla y Sandra Minvielle

I995 "Sociedades geográficas y delimitación del territorio en la construcción el Estado-Nación argentino", trabajo presentado en $\mathrm{V}$ Encuentro de Geógrafos de América Latina, La Habana, Cuba, 1995, disponible en <http://descargas-api,educ.ar/repositorio/Download/file?file_ id $=05573$ cod-7aob-IIeI-82Ie-edi5e3c494af $>$.

Zusman, Perla

1999 "Representaciones, imaginarios y conceptos en torno a la producción material de fronteras", en Revista Bibliográfica de geográfica y Ciencias Sociales, Universidad de Barcelona, núm. I49, <http:/www.ub.es/geocrit/b3w-I49.htm >.

2013 "La Geografía Histórica, la imaginación y los imaginarios geográficos", en Revista de Geografía Norte Grande, núm. 54, Instituto de Geografía, Universidad Católica de Chile. 